\title{
Desiring Dexter: the pangs and pleasures of serial killer body technique
}

\author{
Stephanie Green ${ }^{1}$
}

School of Humanities, Griffith University, Gold Coast, Australia

\begin{abstract}
The television series Dexter uses the figure of appealing monstrosity to unfold troubled relationships between corporeality, spectatorship and desire. Through a plastic-wrapped display of body horror, lightly veiled by suburban romance, Dexter turns its audience on to the consuming sensations of blood, death and dismemberment while simultaneously alluding to its own narrative and ethical contradictions. The excitations of Dexter are thus encapsulated within a tension between form and content as ambivalent and eroticised desire; both for heroic transgression and narrative resolution. Arguably, however, it is Dexter's execution of a carefully developed serial killer body technique which makes this series so compelling. Through an examination of Dexter and his plotted body moves, this paper explores the representations of intimacy and murderous identity in this contemporary example of domestic screen horror entertainment.
\end{abstract}

\section{Keywords:}

Dexter, body-technique, desire, crime television, horror

1 stephanie.green@griffith.edu.au 
Launched in 2006, the television drama series Dexter has been a ratings recordbreaker for its network producers (Showtime, CBS 2007-2011). The eighth episode of its first season ('Shrink Wrap', 1: 8) broke the Showtime record for a drama series episode (Hollywood Reporter 2007). By Season Four Dexter was attracting in the order of 2.6 million viewers (Hibberd 2011), with ratings continuing to climb through Season Five, while its star Michael C. Hall has captured a quiver of awards for his controversial role. Equally, the series has drawn acclaim from critics, who have been largely undeterred by its troubling premise in which a forensic investigator fatally 'solves' those criminal cases that the police can't find a way to prosecute (Howard 2010). Recognising the ambiguities and contradictions that Dexter encompasses, my discussion willexplore embodiment and intimacy in this contemporary example of domestic screen horror entertainment. More specifically, I willargue that Dexter's appeal resides, at least partly, within its representation of the main character's discomfortingly expert serial killer body technique.

Dexter Morgan is a compulsive serial murderer, a lone vigilante with a rigid 'Code of Practice', who works for the Miami Police by day as a blood spatter analyst. From Season One, he is presented as an honourable murderer, a comical control freak with a sharp sense of irony who is never quite as much in control as he would like to be. His boyhood fascination with blood and death has been repurposed through special training in the Code: a failsafe method for execution invented by his adoptive father, Harry Morgan (James Remar), to bring to account those perpetrators of major crime who evade the law. Dexter uses his access to police databases to track his prey, then prepares a 'kill room' in which he and his victim come face to face in one final intimate moment of mutual recognition as he stabs them through the heart. Like Victor Frankenstein's monster (Shelley 1980), Dexter is his father's creature, a living being formed from the shards of the dead (Howard 2010, 63; Green 2011). Rescued as a baby from the ghastly crime scene in which his mother is dismembered with a chain saw, Dexter is `enhanced by trauma and training to take revenge on the killers that can't be caught. He therefore does what his colleagues at the Miami Police Department cannot do by virtue of the rules of civil law enforcement. Through an elaborately planned sequence of illicit steps, he exercises the ultimate punishment without remorse. His capacity for killing renders 
him almost superhuman, a virtual human cyborg who acts, as it were, 'beyond the reach of human corporeality, physically and psychically’ (Cranny Francis 2008).

Dexter's executions are not always judged with superhuman accuracy, however. In Season Three he kills by accident ('Our Father', 3:1), while in Season Four he kills a photographer who later turns out to be innocent of the murder of his young models ('Slack Tide', 4:7). These events serve partly to increase narrative tension and partly as a disturbing reminder of Dexter's problematic personal and moral stance. Although the overwhelming public response to Dexter has been positive since its broadcast network release on CBS, the series has attracted criticism for its problematical ethics. Its most prominent critic has been the American Parents' Television Council which issued a warning against the show on its website, as millions of Americans were happily watching each week (Winter 2008). So, why do we keep watching? What's so seductive about Dexter? Why do so many viewers and critics alike concur with Boston Globe's Matthew Gilbert, who commented in response to the first season that Dexter is 'fiendishly excellent ... so much more than its body parts' (2006). Or, with blog writer Paul Levinson who called the series 'one of the great titans of television' (2009).

One aspect of the series' success flows from its satirical sword play with the vigilante detective genre and with the spectacular conventions of serial killer television drama, in which narrative ambiguity is sustained through episodic anticipation. In concert with self-conscious irony, the displaced eroticism of the kill scenes gives each episode its potent flaw. Through a tidy display of body horror, lightly veiled by plasticwrapped suburban romance, the series turns its audience on to the troubling stimulants of blood, death and dismemberment while simultaneously alluding to its own narrative and ethical contradictions. Dexter's reflexive performance of serial killer body technique thus encapsulates a tension between form and content as ambivalent and eroticised desire; both for heroic transgression and narrative resolution. It is the figure of Dexter as the troubled embodiment of projected desire that this paper will address.

Within a television series which centres upon the body of the victim as locus of evidence in solving crime, Dexter as a corporeal figure may be overlooked, yet in various ways the embodiment of this seemingly unassuming character is central to the series and its seductive power. Neatly muscled, carefully exercised, well-tuned, seemingly naive and unassuming, Dexter's physical fitness renders him attractive to women, as demonstrated throughout Seasons One to Four in his relationship with Rita (Julie Benz) and in Season Two during his affair with Lila (Jaime Murray). A 
performed by Michael C. Hall, Dexter becomes athletic student and instrument of pleasure. The exposure of Dexter's nude body as a site of intimate eroticism, combined with the educative quality of his relationships with Rita and Lila provide a counterpoint to his father's strict schooling in discipline and restraint. It is Dexter Morgan's specially trained 'fitness' for his task as the secret agent of covert social revenge, however, that points most clearly to the strange eroticism of this television series. A fit body, writes Bauman, is 'a highly sensitive, finely tuned instrument of pleasure, any pleasure' (1998, 116) whose fragmentary gestures express a desire that is nevertheless always threatened by the consuming shadow of decay (121). As a problematical example of Bauman's notion, Dexter performs the body moves, the consuming satisfactions and sensations of the 'kill'. The sensationalism that drives Dexter, and indeed the series itself, is not simply to do with corporeal partiality, however, but with the planned and practised gestures and enactments of the serial killer whose climactic moment is the death of the other: the one who has no Code.

In this sense, Dexter's body can be seen as a site of projected desire in which audience hopes and fears may be concentrated. The series plays on its depiction of middle class American normality as threatened by a rising tide of crime, death and violence, by aligning the audience point of view with that of its serial killer hero. Elayne Rapping argues that one of the roles of crime drama is to "mark out and delineate the contours of 'deviance' by sketching a portrait of a 'normal' and legal standard against which the 'outlaw' is measured $(2003,66)$. Dexter unsettles this dichotomy. His arch confessions, however, provide a mechanism for viewers to enjoy the series without fully accepting the terms of its disturbing rationale. Indeed the voyeuristic pleasures offered by the series rely on a highly self-conscious handling of its inherent contradictions and on Dexter's ironical, back-handed narration of events. As Simon Brown and Stacey Abbott suggest, the device of positioning the audience to identify with the serial killer has been one of the factors that has attracted most criticism of the series, but is also the essence of its potency 'lending greater impact to those moments of visual excess' and reconstructing the aesthetics of horror spectacle (2010, 209-210). Further, Brown and Abbott argue, the way that Dexter exploits but distances itself from body horror aesthetics allows the series 'to negotiate its transgressive premise' (208). Dexter's kill scenes are the episodic climax of excitation, as Dexter breaches each victim's bodily integrity, causing irredeemable disarray. At the same time his coded actions are gestures of restitution in which danger is averted or revenge for suffering attained. The 
immersion of the fatal hunt narrative within middle class normalcy serves to heighten these moments of visual excess. Dexter uses each of his kill rooms as a 'narrative space' within which 'the murder is the culmination of the performance' (Brown and Abbott, 219) and the passing moment of narrative resolution.

There is one body that always remains, however: one corporeal being that must live, in order for the story to continue. Jeffrey Jerome Cohen observes that, 'the monster's body quite literally incorporates fear, desire, anxiety and fantasy' $(1996,4)$. As this paper proposes, Dexter's appeal, including its displaced eroticism, resides within its representation of Dexter's discomfortingly expert body moves and the challenges he overcomes in order to practice his specialised technique.

The work of early twentieth-century sociologist Marcel Mauss offers a foundational reference point here (1947). Mauss introduced the notion of body technique, later elaborated by Pierre Bourdieu as an expression of Habitus (1977), to locate social functions and meanings: habitual gestures and practices, of labour, worship, nurturance, sexuality or play. These practices are traditional, passed on through generations, yet they are learned and may also be developed or changed over time as new understandings, contexts and adaptations arise (Mauss in Schlanger 2006, 98-100), thus creating, as Elspeth Probyn puts it, 'a mutual exchange' between the physical body and social $(2005,56)$. This notion has relevance for Dexter in various ways, including the hero's coded 'contract' as a trained vigilante. In one sense, the figure of Dexter can be regarded as a disturbing exploration of the social contract itself, in which privately embodied action constitutes a public discourse of transgressive citizenship. Probyn observes with reference to the work of Bruno Karsenti that, 'Mauss's project is nothing less than 'an enquiry into the principals on which the human being is 'assembled' ... a reorientation of the conceptualization of the social.' (57). Dexter is a version of such a project himself as a 'reassembled' being, reconstituted from among the bloody fragments of his mother's murdered body and trained for his crime warrior role ('Popping Cherry', 1.3).

Under Harry's tutelage, Dexter acquires a repertoire of covert surveillance techniques and self-protective routines which help him to judge the timing and geography of the culmination scene. He practices facial expressions, gestures and phrases in order to fit in with society ('Let's Give the Boy a Hand', 1:4) and keep his killer identity secret. Dexter's embodiment as the serial killer is signified by a special kill costume and personal tool kit. Many of his techniques can be recognised as 
commonly rehearsed tropes of serial murder in popular screen drama, which include stalking the victim, the death scene tableau, the kill ritual, and securing the trophy - in his case a blood slide taken from each victim. Dexter's body techniques may also be regarded as a form of technology: the methodological application of skills and knowledge to achieve a 'practical' solution. Jonathan Sterne argues that 'technologies are essentially subsets of Habitus - they are organized forms of movement' $(2003,371)$ which embody social forms and actions. Dexter's body technique reproduces complex social relationships, assumptions and - often disturbing - values and beliefs, but their episodic return, the minute transformations of rehearsal, also allow for the possibility of a gradual remaking of the terms of his practice.

Initially, at Harry's urging, Dexter strives for solitude and distance from others, maintaining a degree of structured superficiality in his relationships. Yet, for all his night-covered secrecy and rhetorical alienation from authentic social connection, as the series progresses Dexter becomes increasingly embedded within the social sphere of community and family. The routines he practices to mask his alter ego are continuingly threatened as his dual spheres of operation threaten to overlap. For example in Season One, Dexter tries to help a Cuban woman who works with Rita and discovers a couple has been murdering illegal immigrants after taking money from them ('Love American Style', 1.5). In Season Three, when Dexter forms a covert alliance with Assistant District Attorney Miguel Prado (Jimmy Smitz), Prado’s wife Syl (Valerie Cruz) complains about his night time disappearances and Rita suspects that Prado is having an affair ('Easy as Pie', 3.7). Similarly, in Season Five his relationship with rescued rape victim Lumen Pierce (Julia Stiles) is discovered by his step-daughter Astor Bennett when she tries to protect a friend ('Teenage Wasteland', 5.9). While appearing to rehearse a discourse of individualistic vigilante justice, the thrills and spills of Dexter's illicit operations are at once profoundly social and discursive. As Nathan Schlanger suggests with reference to Mauss, 'the coordination of articulated motions' through which meaning is conveyed, 'confirm the social nature of the Habitus' (199).

The Habitus of Dexter is, of course, the familiar fictionalised one of middle class television America, in which violent crime is a disproportionate and sensationalised threat, as consumed nightly with rampant fascination by millions of viewers. In one sense, the dark super-hero figure of Dexter Morgan can only exist in television-land. In another sense the impact of the series is its ability to stir very real fears and social anxieties. Dexter rests partly on a disturbing presumption: that the social order is in 
disarray, beyond the scope of police enforcement, and that this tear in the fabric of the democratic rule of law therefore permits restitution to be achieved by other means. The implications of such a presumption are of course potentially horrific. Indeed the producers of the series were forced to defend the series when Peter Twitchell, alleged murderer of Johnny Brian Altinger, was described in the media as a Dexter copycat (Vancouver Sun 2008). Nevertheless, the presumed dangers and desires of contemporary urban society provide the series with a frisson of fictionalised authenticity and anticipation. In this sense, Dexter could be considered as a radical figure of imaginary potency and revenge which, as Elizabeth Grosz argues, marks where the 'discourse is unable to admit its founding assumptions' (1989, xix). Dexter suggests on the one hand that the excitations of fictional murder can stand in for the satisfactions of judicial vengeance and on the other, as so many American television narratives have before, that super-heroic individual action offers a solution to rampant violence and crime.

At the time of writing, Dexter has completed five seasons, with a sixth in release. Originally intended for cable release, Dexter's first season was heavily edited for graphic violence in order to allow it to be shown on network television as a salve for the American Screenwriters strike (Ellis 2008). Seasons Two and Three contain the degree of explicit grotesquerie to which viewers are exposed, although the implied violence of the kill scenes take them all the way to the key stroke of execution. The opening sequence of Season Four raises the level of explicit sexual violence in Dexter with the first appearance of Arthur Mitchell (John Lithgow) as the 'bathtub' or Trinity killer ('Living the Dream', 4.1). In all five seasons to date, however, key narrative and visual motifs remain consistent. Each anticipates and delivers a spectacular kill scene, each catches a murderer, solves a mystery, relieves the audience, and momentarily restores the social order - albeit a trifle blood-stained - providing viewers with that tidy feeling of having wiped down the benches and taken out the trash.

Linda Williams describes screen horror entertainment as a 'body genre' in which excess and sensation are exercised through spectacle (1991). As with all body genres, including erotica, as soon as the spectacle of one climax is over, another begins to build. Adaptive repetition is, of course, key to compulsive voyeurism. Alison Pierse discusses the influence of film noir in Dexter, where the narrative arc of the show can be seen as a form of 'masochistic repulsion-compulsion' (2010, 203). Secrecy and revelation, desire and its satisfaction: these are the building blocks of all narrative forms, and Dexter is, if 
nothing else, respectful to narrative imperatives. The series succeeds by sustaining a tension between spectacle and narrative impetus. Its ensemble cast and interwoven plot lines supply a counter-narrative to the enthralling lacuna of body horror. It is the anticipation of visual excess, however, the death scene of the criminal victim, that propels each episode forward. As with other body genres, such as erotica, the series indulges in the surpassing of limitations, freedom from laws and moral strictures. It uses techniques of audience excitation and manipulation. Its central motif is blood, a highly resonant visual element of the show's public positioning, as Angela Karpovich observes with reference to the vivid red splash of its title as part of its 'defining graphic identity' (2010, 31). Blood is Dexter's reason for being, his professional medium, the fluid object of his desire, and the evidence of the unbounded body through which he constantly seeks restitution. But red is also the colour of play. Karpovich points out that the opening credits of Dexter offer a colourful visual irony that reminds us that we are about to enter the realms of fantasy, that we are - above all - being entertained (29).

A narrative figure of wish-fulfilment and release, Dexter is presented both as the super-heroic 'Dark Defender' (Season 1.8) and the devouring Dark Passenger the shadow self with a ceaseless desire for blood, death and revenge ('Truth be Told', 1.11). He is at once the embodiment of a transgressive desire for untrammelled action and the avenging angel of social restitution - a role conferred upon him by the long dead Harry Morgan and one that, from time to time, he resists. Dexter has desires of his own, including for friendship, family and fatherhood. To some extent these social roles offer him the guise of social normality that becomes part of his armour as Miami's suburban revenge warrior. It is his avowed yearning for a darker comradeship, however, to be fully known and understood, which repeatedly brings him into conflict with Harry's protective Code. In Season One, for example, Dexter duels with the Ice-truck Killer, seeking connection, but finally chooses the Morgan Code and the life of his lawabiding step-sister Debra over that of his brother, an anarchic serial-killer Brian (Christian Camargo) disguised as the surgeon Rudy Moser ('Born Free', 1.12). In Season Three, Dexter forms his dangerous friendship with Assistant District Attorney, Miguel Prado whose lust to apply a final solution has no limits ('Si Se Puede', 3.6). While throughout Season Four, Dexter pursues his fascination with the 'Trinity' killer (John Lithgow), ignoring James Remar's translucent appearances as a modern day Hamlet's ghost, warning of doom and urging his son to action. 
Consistently represented both as the product and the instrument of a powerful desire for criminal vengeance, Dexter maintains his sotto voce pantomime intimacy with the viewing audience, commenting on the unfolding action and revealing his thoughts and intentions towards the other characters. This device creates the illusion that there is perhaps a 'true' Dexter, the one that only we viewers can know, for whom the roles of suburban dad and serial killer are both in some sense assumed for the purpose of the story. Dexter's arch references to his own neat monstrosity ('Left Turn Ahead', 2.11) arguably foreground the show's use of Gothic excitation and ambiguity to engage its audience. It is the figure of Dexter as the embodiment of narrative desire, however, which provides the locus of audience anticipation and ambivalence. A conflicted serial killer who goes the distance to 'solve' society's problems, by way of a trained compulsion to kill, Dexter's coy deployment of corporeal potency remains the clue to the show's seductive power.

Clad in conventional chinos and loose cotton shirts, and the protective mask of his goofy smile, Dexter carries on his profession as a blood spatter expert as a daytime disguise. But on those dark special nights when he puts on his black kid leather gloves and khaki stretch cotton vest, the Dark Passenger comes out to play. Whenever he appears in this costume, with its subtle tactical allusions to the figure of the Hollywood cat burglar and the guerrilla warrior, the audience is given a visual cue of anticipation that a death is planned: a reminder of Dexter's insatiable desire for death and blood. At the same time, the costume also refers to his original training in the Morgan Code, the measures of strained orchestration and execution that he must perform in order to be allowed his final satisfaction.

Dexter`s serial killer costume therefore works both as camouflage and revelation. In these moments, as played by Michael C. Hall, Dexter's physical persona changes. The dust-coloured outfit clings to his upper body, allowing it to move without disguise or restraint. Dressed to kill as the Dark Passenger, the embodiment of the demonic self, he becomes lithe and fierce-faced, looming out of the dark to stab his victims in the neck with a paralysing anaesthetic, as when he overcomes Miguel Prado in Season Three ( 'Do You Take Dexter Morgan', 3.12). In Season Four he describes the Dark Passenger as 'a trapped coal miner always tapping, always letting me know it's still in there, still alive' ('Remains to be Seen', 4.2). The Dark Passenger is never privileged as the authentic Dexter Morgan, maintaining the generic convention of the serial killer's 'terrifying normality' (Jarvis 2008, 329). At the same time, the accoutrements of 
Dexter's carefully coded identity reflexively allude to audience complicity in the disturbing narrative pleasures of bodily consumption, death and dismemberment in which the series indulges.

The importance of Dexter's dress code as an aspect of body technique is first articulated in Season Three, when Dexter starts to train Assistant District Attorney Miguel Prado for the kill. The displacement of the ADA's pressed office shirt for the clinging night-time outfit is one of the key accoutrements of Prado's supposed transformation. It also signals the intimacy of exposure that develops between these characters ('Si Se Puede', 3:6), and which Dexter later replicates with Lumen Pierce in Season Five ('In the Beginning', 5.10). Prado is eager to practise his newly learned skills, but without accepting its supposedly 'ethical' limitations, becoming an undisciplined and uncontrollable force of darkness which Dexter eventually feels forced to destroy. During the fatal exchange between the two men at the end of Season Three, Prado is bound to a table and stripped of his kill costume - the key symbol of their intimacy. Dexter tells him, 'I had higher hopes for you, for us, but I finally just have to accept it. I'll always be alone.' ('I Had a Dream', 3.11). Prado tries to convince Dexter to let him go, by manipulating Dexter's longing for acceptance and recognition as he has done throughout the season: 'I know you. I accept you. I accept you, Dexter, like a brother.' Dexter replies succinctly, 'I killed my brother' ('Do You Take Dexter Morgan', 3.12).

The intimacy between Dexter and Miguel Prado is one of several instances of Gothic doubling in the series, in which Dexter engages with an even darker opponent. His brother Rudy's playful but deadly stalking of Dexter throughout Season One, the game of pursuit and capture that unfolds between Dexter and Sergeant James Doakes throughout Season Two, and Dexter's fascination with the 'Trinity' killer in Season Four, all point to Dexter's desire to be able to connect with someone like himself. But, for all his private longings, Dexter's identity can never become entirely split from his public persona as Mr Average American: white, heterosexual, middle class, seemingly law-abiding, with all the normal social anxieties and expectations of his milieu. Although towards the end of Season Four, he is immersed in fatherly domesticity and has hopes of being liberated from the weight of his Dark Passenger altogether, by Season Five Rita's murder has shattered that hope. Equally unable to abandon his links with his family and workplace community, Dexter seeks atonement and eventual intimacy with Lumen, the revenge-seeking victim of extreme sexual violence whom he 
rescues from her fate as a one of Boyd Fowler's 'barrel girls' ('Beauty and the Beast', $5.4)$.

The rendering of Dexter Morgan as a corporeal figure cannot be fully addressed without further reference to the question of his sexuality and to the eroticism of his murderous conquests. Beth Johnson points out that, at the outset of Season One, Dexter appears to be asexual $(2010,79)$ : a nerdish forensic scientist with serial killing for a hobby. He does however develop 'intimate relationships with his victims, stripping them, physically containing them, demanding that they look at him and at images of those they have murdered' (81). His killings are, Johnson argues, 'attempts to produce jouissance (an unbearable pleasure)', while the phallic presence of knives, blades and other serial killer accoutrements as exemplified in the opening credits sequence, provide a visual repertoire of violent sexual symbolism (81).

Inexperienced in relationships with women and trained by his father Harry Morgan to guard his privacy, Dexter is slow to embark upon a sexual relationship with Rita. As a sufferer of domestic violence at the hands of her ex-husband Paul, at the outset of their relationship Rita is delighted to have found a boyfriend who appears to be willing to date and wait. His sexuality therefore remains dormant, until awakened by Rita as her sexual confidence returns ('Let's Give the Boy a Hand', 1.4).

In Season Two, Dexter is seduced by the unpredictable pyromaniac Lila (Jaime Murray), who briefly introduces a wild erotic charge into Dexter's night life ('Dex, Lies and Videotape', 2.6). His appetite for the kill is far from assuaged by his athletic encounters with Lila, however, whose allure is partly that she isn't horrified by his dark side. No longer camouflaged by khaki or crumpled cotton, Dexter's muscular nakedness is revealed. Dexter finds Lila's fiery anarchism too explosive and returns to the strictures of the Morgan Code as the measure of his survival. His affair with Lila causes a momentary bump in his relationship with Rita, but Dexter is saved by his usual flair for keeping up appearances, when he follows Lila to London and ends their relationship - permanently - with phallic precision ('The British Invasion', 2.12).

These climactic moments in Dexter offer a pointed multivalence, in which we, the viewers, are also implicated in the performance and thus in the Gothic excitations of serial killer body technique. Dexter`s cover is arguably that it makes problematic the impulses that it also exploits, using humour and visual irony to entertain and comment on social values and conditions. The series forces its audience to confront the experience of amusement and pleasure in watching orchestrated death and the unreal 
horror of bodies in disarray. Its stylised ironies and narrative juxtapositions allow us to return with relief to the familiar quotidian disarray of ordinary domestic life, represented in the series by the middle class suburban family home. Dexter exploits this need for relief, however, punctuating the horror narrative of the Dark Passenger with occasional comic misadventures when Dexter's well-rehearsed serial killer body technique seems to fail. At the outset of Season Four, for example, he crashes his car hurrying home from an interrupted kill scene, exhausted from juggling new fatherhood and his husbandly duties in the bedroom with Rita with his secret serial killer "night shift'. The episode is sustained by the comic tension of Dexter's temporary amnesia from a head trauma after the crash, which prevents him from remembering where he has stashed the body of his last perpetrator/victim ('Living the Dream', 4.1). The hidden location of the body is revealed, inevitably, by a blood stain which, like the stain in Oscar Wilde`s late-Victorian parable Canterville Ghost (Penguin, 2010), refuses to be erased.

With this incident, Dexter proves to himself that domesticity and fatherhood have not caused him to forget his training in the Code. Even at a moment of crisis he has found a way to keep the bodies of evidence - those of his own Dark Passenger and the victim his latest vigilante excursion - hidden from detection. At the same time, Dexter's enmeshment in the social sphere is repeatedly reinscribed through error or misjudgement. Probyn points out that Maussian body technique allows for the fact 'that humans habitually do things wrong' (58), suggesting that the social and physical spheres are linked as much through faulty rehearsal as through perfect execution. Dexter's kill routine is again unsettled by comic tension in Season Five, when his tranquillising needle draws return fire from Boyd Fowler's animal dart gun ('Practically Perfect', 5.3). Both men are taken to hospital unconscious, but Dexter catches up with the 'barrel-girl' gang member a few hours later at his house. In this sequence Dexter's body technique is disrupted in two ways. The attempted kill takes place during daylight and Dexter wears a pale blue polo shirt instead of his serial killer outfit, perhaps confirming that the khaki costume, has a special narrative potency. More importantly, the relocation of the murder scene leads to his first encounter with Lumen Pierce and the unique intimacy that develops between them (5.3).

Arguably, the theme of intimacy becomes central to Dexter as the series progresses through Seasons Four and Five. While its portrayal of seria killer body technique can be approached in terms of an erotic practice, as patterned gestures of excitation enacted 
through pursuit, conquest and release, it is Dexter's desire for intimate recognition from someone who understands him that begins to drive his actions. This intensifies in Season Five when Dexter participates in Lumen's program of revenge against the men who assaulted her. At the end of Season Five, however, Lumen leaves Miami and Dexter turns to fatherhood for consolation ('The Big One', 5.12). The faulty connections that Dexter experiences in his public relationships never fully satisfy his desire, however, and remain shadowed by the secret and irresistible intimacies of stalking, revelation and execution.

The pleasure of Dexter lies partly in how the series walks the line between screen horror and cosy domestic television. While the series creates layered narratives through a network of relationships connected by its eponymous central character, ultimately it is the practice of Dexter's highly specialised body technique that drives each season's narrative arc. The kill scenes, with their plastic curtains and tableau of heart-stabbing ritual sacrifice, never display the wholesale gore of butchery, but they do reveal the climactic point of admission when the perpetrator is forced to face his or her nemesis and blood is finally shed. As Brown and Abbott observe, 'the horror lies in the art of the performance' (219), in which the boy-next-door super-hero monster killer completes his prescribed pattern of movements and gestures, bringing each season to its unsettling yet strangely satisfying conclusion.

\section{Works Cited}

ACESHOWBIZ: http://www.aceshowbiz.com/celebrity/michael_c_hall/awards.html

Baumann, Zygmunt. 1998. Life in fragments: essays in postmodern morality. Oxford: Blackwell.

Bourdieu, Pierre. 1977. Outline of a Theory of Practice. Cambridge: Cambridge University Press

Cohen, Jeffrey Jerome, ed.1996. Monster theory: reading culture. Minneappolis: University of Minnesota Press.

Cranny Francis, Annie. 2008. From extension to engagement: mapping the imaginary of wearable technology. Visual Communication 7.3: 363-382.

Ellis, Ray. 2008. Dexter and the writers' strike revisited. BlogCritics, 24 January. http://blogcritics.org/archives/2008/01/24/203709.php/ 
Gilbert, Matthew. 2006. Stylishly graphic 'Dexter' pleases with a killer twist. Boston globe, September 30.

http://www.boston.com/ae/tv/articles/2006/09/30/stylishly_graphicdexter_pleases_with_a_killer twist/.

Grosz, Elizabeth. 1991. Sexual subversions. Sydney: Allen \& Unwin.

Hibberd, James. 2009. Hollywood reporter, December 14.

http://www.hollywoodreporter.com/hr/content display/television/news/e3idd7290014145867f5 e18baf9eb33bf5e/

Hibberd, James. 2010. Hollywood reporter, November 30.

http://www.hollywoodreporter.com/blogs/live-feed/dexter-season-finale-ratings-hit-52755

Hollywood reporter. 2007. Dexter scores killer numbers for Showtime. Reuters, November 21. http://www.reuters.com/article/idUSN2164143020071121/

Howard, L. Douglas, ed. 2010. Dexter: investigating cutting edge television. London: I. B. Tauris.

Jarvis, Brian. 2007. Monsters inc.: serial killers and consumer culture. Crime, media, culture 3.3: $326-344$.

Johnson, Beth. 2010. Sex, psychoanalysis and sublimation in Dexter. In Douglas L. Howard, ed. Dexter: investigating cutting edge television, 78-95. London: I. B. Tauris.

Karpovich, Angla. 2010. Dissecting the opening sequence. In Douglas L. Howard, ed. Dexter: investigating cutting edge television, 27-42. London: I. B. Tauris.

Levinson, Paul. 2009. Dexter season four: sneak preview non spoiler preview: fabulous! Paul Levinson's infinite regress. September 13. http://paullevinson.blogspot.com/2009/09/dexterseason-4-sneak-preview-non.htmll

Mauss, Marcel. 2006. Technology (1935/1947). In Nathan Schlanger, ed. Techniques, technology and civilization, 97-140. Oxford: Bergahn Books. Originally published in Dominique Lussier, trans. Technology Manuel d'ethnographie, 29-83 (Paris: Payot, 1947).

Pierse, Alison. 2010. In a lonely place: Dexter and film noir. In Douglas L. Howard, ed. Dexter: investigating cutting edge television, 189-204. London: I. B. Tauris.

Probyn, Elspeth. 2005. Blush: faces of shame. Minneapolis: University of Minnesota Press.

Rapping, Elayne. 2003 Law and justice as seen on TV. New York: New York University Press.

Shelley, Mary. 1980. Frankenstein, or the modern Prometheus. Oxford: Oxford University Press.

Sterne, Jonathan. 'Bourdieu, Technique and Techology,' Cultural Studies 17:3/4 (May/July 2003): 367-389.

Vancouver Sun. 2008. Alleged copycat killing is nightmare come true for Dexter producer. Canada.com, November 10. http://www.canada.com/vancouversun/news/story.html?id=43336322-4a85-4d22-a55d$\underline{\text { 9d96d7f658f1 }}$ 
Williams, Linda. 1991. Film bodies: gender, genre, and excess. Film Quarterly 44.4: 2-13.

Winter, Tim. 2008. Parents Television Council, America.

http://www.parentstv.org/ptc/shows/main.asp?shwid=2695/ 